\title{
ENSAIOS SOBRE A ECONOMIA DA PROVÍNCIA DO CEARÁ DURANTE DO SÉCULO XIX
}

\author{
George Henrique de Moura Cunha \\ Doutor em Economia pela Universidade de Brasília - UNB. Departamento de Economia, \\ Universidade de Brasília, ECO/UnB \\ georgehmc@outlook.com
}

RESUMO - Este trabalho pretende resgatar a discussão do papel das condições climáticas sobre a economia cearense no século XIX. Descreve a passagem de uma economia de subsistência para uma economia monetizada baseada no algodão, até o impacto da grande seca de 1877 a 1879 na economia local.

Palavras-Chave: História econômica do Ceará; Cotonicultura; Seca de 1877 a 1879.

\section{ESSAYS ON THE ECONOMY OF THE PROVINCE OF CEARÁ DURING THE 20TH CENTURY}

\begin{abstract}
This paper intends to rescue the discussion of the role of climatic conditions on the economy of Ceará in the nineteenth century. Describe the transition from a subsistence economy to a monetized economy based on cotton, to the impact of the great drought of 1877 to 1879 on the local economy.
\end{abstract}

Keywords: Economic history of Ceará; Cotton Economy; Drought from 1877 to 1879.

\section{INTRODUÇÃO}

Ao longo do tempo, os períodos de seca têm afetado continuamente a história econômica do Ceará. Os primeiros registros provem do início no século VIII, com a grande seca de 1711. Segundo Theophilo (1922, p 11-12) a partir deste ano, três grandes secas afligiram o território cearense neste século: de 1723 a 1727, de 1744 a 1745, e 1776 a 1777. Em uma perspectiva de tempo mais ampla, entre 1700 e 1850, $20 \%$ deste período ou trinta anos foram registradas precipitações abaixo da sua média histórica.

Embora a seca fosse um fenômeno comum na vida dos seus habitantes, não havia um preparo da sociedade para os seus efeitos. Assim, se houvesse um período chuvoso que garantisse uma boa safra, a vida dos sertanejos seria melhor, porém se as chuvas fossem insuficientes, a sobrevivência estaria ameaçada. O clima do Ceará é bem diferenciado, no litoral a humidade é mais elevada e a quantidade de precipitações maior, ao contrário do interior, onde as chuvas são mais escassas. Ao longo de tempo, o regime pluviométrico do Estado do Ceará tem se caracterizado pela irregularidade.

O objetivo deste trabalho é tentar resgatar a discussão sobre as transformações ocorridas na economia cearense entre o começo do século XIX até a grande seca de 1877 a 1879 . Ao longo deste período, modificações na estrutura econômica da região possibilitaram um surto de crescimento econômico nunca antes verificado, com a introdução do cultivo do algodão. 
Também é destacado a importância do clima, para o sucesso ou fracasso das lavouras em uma sociedade cuja maioria dos seus habitantes se assentava nos campos.

\section{A ECONOMIA CEARENSE NOS PRIMÓRDIOS DO SÉCULO XIX}

Desde o processo de colonização da região, que abrange todo o século XIX e parte do século XX, a economia da Província do Ceará esteve fundamentada na atividade pecuária e na agricultura de subsistência, havendo, porém, um breve momento onde a cultura do algodão e suas atividades correlacionadas proporcionaram ao interior da região um período de euforia econômica. Neste contexto agrário, as relações sociais eram determinadas entre a submissão do sertanejo com o seu senhor de terras e o controle deste na vida da coletividade. No período de escassez, a estrutura social baseado controle político dos grandes proprietários de terras, conseguia atenuar os efeitos negativos da seca sobre a população interiorana. Não havia entre os governantes locais de uma percepção e interesse da necessidade de o Estado intervir para ajudar os mais prejudicados.Mesmo que houvesse, as dimensões territoriais e a escassa população distribuída esparsamente ao longo deste espaço geográfico, provavelmente tornariam inócuas quaisquer medidas adotadas.As relações sociais entre os camponeses e os grandes proprietários de terras são descrita em Neves (2007, p. 77):

\footnotetext{
Os homens que habitavam essas terras semiáridas organizavam-se em fazendas de criação. Dividiam seu tempo entre a lida com o gado e uma pequena agricultura de subsistência, permitida pelos donos das terras, orgulhosos senhores que mantinham laços paternalistas - baseados na reciprocidade e na lealdade pessoas - com seus "moradores".
}

As técnicas agrícolas eram rudimentares e as sementes plantadas no campo garantiam ao camponês uma colheita rápida, porém vulneráveis as oscilações do clima, tornando as condições de vida dos camponeses extremamente dependentes das oscilações proporcionadas pela natureza. Se os invernos fossem favoráveis, seus resultados possibilitam a manutenção de suas famílias ao longo do ano, porém elas não geravam grandes excedentes necessários para a comercialização em outros mercados fora da Província.

Na pecuária, vigorava a prática da "quarta" uma divisão entre os proprietários dos rebanhos de gado e seus vaqueiros. Neste costume, para cada quatro bezerros nascidos, um pertencia ao vaqueiro. Está forma de remuneração, possibilitava em conjunto com a agricultura de subsistência, uma pequena possibilidade para os sertanejos de ascensão social (NEVES, 2007, p.78).

A economia pecuária era fundamentada no trabalho livre, que dada as suas características de operação, inviabilizava se o emprego de trabalho escravo. A curtição de solas e pelicas era praticamente a única atividade industrial de destaque na província, sendo realizada por meio de

REVISTA ECONOMIA POLÍTICA DO DESENVOLVIMENTO $\quad$ Maceió - AL $\quad$ V.5 N.7. $\quad$ JUNHO/2018 $\quad$ P.98-111


técnicas rudimentares no interior.Os dados disponíveis sobre a pecuária cearense apontam que seus valores eram bem reduzidos, quando comparados com outras mercadorias, isto acarretava pouca importância na composição das exportações. Em outras palavras, isto representava um forte indicio que de que a produção de gêneros alimentícios era destinada, em sua maior parte, ao abastecimento interno da região e para a subsistência.

Os roçados feitos pelos agricultores proporcionavam uma cesta de produtos que garantia a sua sobrevivência aos habitantes da província. De forma geral, eram plantados, milho, feijão, arroz e mandioca, cana de açúcar. A dieta do sertanejo era complementada, com carne salgada, mel e frutas e legumes. Além disso, se o camponês estivesse habitando próximo ao litoral, os pescados podem ser incorporados a sua dieta. Também deve ser acrescentada a criação de galinhas e porcos.

Sua produção era destinada, tanto ao mercado interno como externo, na confecção de solas e pelicas (GIRÃO: 2010; 150). Nas fazendas a principal atividade era a criação do gado bovino, com a finalidade de produzir couro. A indústria do couro proporcionava ao camponês uma renda monetária que permitia comprar nas feiras comerciais, mercadorias e serviços no qual não dispunha de acesso ou que não poderia produzir.

\section{Gráfico 1}

Rebanho Cearense: 1827 a 1860

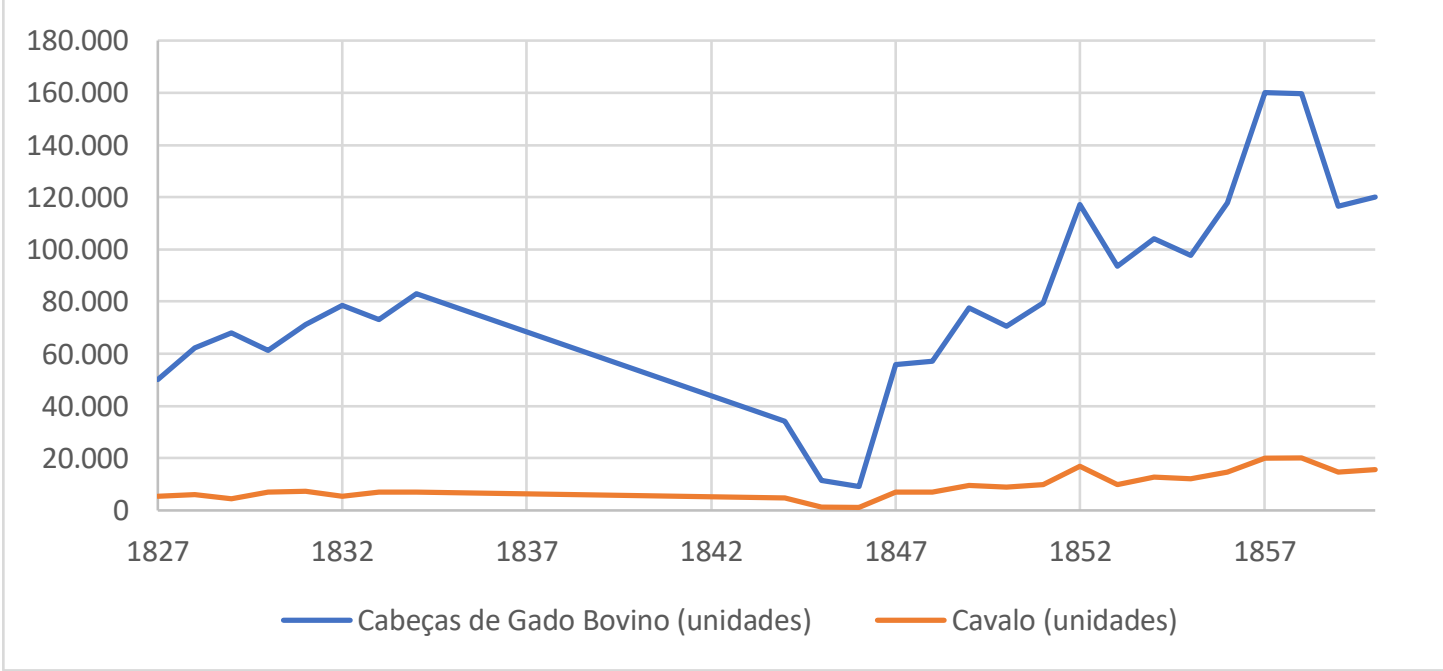

Fonte: BRASIL (1997).

Embora as estatísticas fiscais para a Província do Ceara sejam precárias, devido em maior parte a escassa cobertura da fiscalização, seus dados são importantes para tentar descrever o nível de atividade deste setor. O imposto sobre a pecuária (Dizimo) representava um instrumento fundamental na arrecadação tributária da província é um indicador da atividade econômica, em uma economia, cuja base econômica se fundamentava na subsistência 
Os dados da tabela seguinte mostram as estatísticas a respeito da arrecadação de impostos sobre a pecuária bovina e muar e uma projeção sobre seus rebanhos. Os dados apontam uma forte influência das condições climáticas sobre o desempenho deste setor. Por exemplo: entre 1827 a 1860, foram 31 anos de invernos considerados normais. Somente em dois anos (1845 e 1846), é que foram registradas precipitações abaixo da normalidade. Ao longo deste período analisado é possível contatar os efeitos negativos da seca sobre a pecuária cearense, pois justamente quando ocorre uma seca, é que se verifica uma queda na produção, preço e arrecadação.

Tabela 1: Estimativa de produção, valor médio do dizimo e preço sobre o gado bovino e muar.

\begin{tabular}{ccccccc}
\hline $\mathbf{A n o}$ & $\begin{array}{c}\text { Dizimo } \\
\text { médio } \\
\text { (em reis) }\end{array}$ & $\begin{array}{c}\text { Cabeças de } \\
\text { Gado } \\
\text { Bovino } \\
\text { (unidades) }\end{array}$ & $\begin{array}{c}\text { Cavalo } \\
\text { (unidades) }\end{array}$ & $\begin{array}{c}\text { Preço médio } \\
\text { de um } \\
\text { garrote (em } \\
\text { reis) }\end{array}$ & $\begin{array}{c}\text { Preço médio } \\
\text { de um potro } \\
\text { (em reis) }\end{array}$ & $\begin{array}{c}\text { Quadra } \\
\text { invernosa }\end{array}$ \\
\hline $\mathbf{1 8 2 7}$ & 4.130 & 50.000 & 5.520 & 4.970 & 6.238 & Normal \\
\hline $\mathbf{1 8 2 8}$ & 5.196 & 62.352 & 6.000 & 4.617 & 6.213 & Normal \\
\hline $\mathbf{1 8 2 9}$ & 5.667 & 68.004 & 4.320 & 6.200 & 8.340 & Normal \\
\hline $\mathbf{1 8 3 0}$ & 5.114 & 61.368 & 7.092 & 6.430 & 8.340 & Normal \\
\hline $\mathbf{1 8 3 1}$ & 5.953 & 71.346 & 7.284 & 5.770 & 10.800 & Normal \\
\hline $\mathbf{1 8 3 2}$ & 6.534 & 78.408 & 5.520 & 5.900 & 10.200 & Normal \\
\hline $\mathbf{1 8 3 3}$ & 6.080 & 72.960 & 6.884 & 7.846 & 10.400 & Normal \\
\hline $\mathbf{1 8 3 4}$ & 6.912 & 82.944 & 7.100 & 7.426 & 14.300 & Normal \\
\hline $\mathbf{1 8 4 4}$ & 2.400 & 34.000 & 4.800 & 5.000 & 10.000 & Seca \\
\hline $\mathbf{1 8 4 5}$ & 710 & 11.360 & 1.280 & 7.840 & 14.000 & Seca \\
\hline $\mathbf{1 8 4 6}$ & 572 & 9.152 & 1.136 & 7.420 & 14.000 & Normal \\
\hline $\mathbf{1 8 4 7}$ & 3.483 & 55.728 & 6.960 & 7.000 & 17.000 & Normal \\
\hline $\mathbf{1 8 4 8}$ & 3.575 & 57.216 & 7.136 & 7.000 & 14.000 & Normal \\
\hline $\mathbf{1 8 4 9}$ & 4.857 & 77.712 & 9.712 & 7.000 & 14.000 & Normal \\
\hline $\mathbf{1 8 5 0}$ & 4.400 & 70.400 & 8.800 & 7.000 & 14.000 & Normal \\
\hline $\mathbf{1 8 5 1}$ & 4.960 & 79.360 & 9.920 & 7.200 & 14.400 & Normal \\
\hline $\mathbf{1 8 5 2}$ & 7.612 & 117.106 & 16.767 & 7.500 & 15.000 & Normal \\
\hline $\mathbf{1 8 5 3}$ & 6.087 & 93.647 & 10.024 & 8.000 & 16.000 & Normal \\
\hline $\mathbf{1 8 5 4}$ & 6.760 & 104.007 & 12.734 & 8.800 & 15.200 & Normal \\
\hline $\mathbf{1 8 5 5}$ & 6.100 & 97.600 & 12.000 & 8.200 & 16.000 & Normal \\
\hline $\mathbf{1 8 5 6}$ & 7.360 & 117.760 & 14.720 & 8.500 & 17.000 & Normal \\
\hline $\mathbf{1 8 5 7}$ & 10.504 & 160.064 & 20.008 & 8.500 & 17.000 & Normal \\
\hline $\mathbf{1 8 5 8}$ & 9.984 & 159.744 & 19.968 & 9.000 & 18.000 & Normal \\
\hline $\mathbf{1 8 5 9}$ & 7.355 & 116.680 & 14.572 & 10.000 & 20.000 & Normal \\
\hline $\mathbf{1 8 6 0}$ & 9.241 & 120.000 & 15.600 & 8.000 & 15.000 & Normal \\
\hline $\mathbf{F o n t e}$ & & & & & & \\
\hline
\end{tabular}

Fonte: BRASIL (1997).

A pecuária e a agricultura proporcionavam ao homem do campo apenas as condições básicas para sua subsistência. As condições internas da economia cearense não permitiam a criação de maior riqueza e consequentemente favorecer a acumulação de capital. Fatores 
externos poderiam tentar alterar este quadro. A oportunidade para que houvesse transformações na base produtiva, surgiria com a indústria do algodão.

\section{O CICLO DO ALGODÃO}

A cultura do algodão foi introduzida em toda a região nordeste no final do século XVIII. De acordo com Silva (2011, p 55), o gado representava a base econômica da região, porém somente o ciclo do algodão é que possibilitou a entrada de um significativo fluxo de capital para o Ceará. Os primeiros registros de exportação do algodão datam de 1810, durante o governo de Borba Alencar. Naquele período, a Província começou a exportar fardos de algodão para a Inglaterra, seguindo em via marítima pelo porto de Aracati em direção ao de Recife, para, a partir de lá, ser transportando para a Inglaterra.

É importante destacar que o cultivo deste arbusto teve uma importância marginal na economia local, durante a primeira metade do século XIX. As principais zonas produtoras eram as localizadas próximas às cidades de Fortaleza, Aracati. Além, das serras da Meruoca (próxima a Sobral), Baturité, Pereiro, Aratãnha e Uruburetama.Essa linha de pensamento é corroborada pelos estudos de Maia (2015, p. 40). Para a autora, o desenvolvimento da cultura algodoeira proporcionou de forma gradual mudanças estruturais na economia da província e na decisão de produção dos pequenos agricultores em cultivar suas roças. Como visto anteriormente, a economia de subsistência era a forma predominante na estrutura produtiva da província e o algodão representava uma oportunidade monetária paras as miseráveis famílias sertanejas. Um bom exemplo disso estava nas exportações de gêneros alimentícios realizadas pelo porto de Fortaleza.

Segundo Silva (2011, p. 83):

"A economia cearense cresceu durante a segunda metade do Século XIX com
recursos advindos das atividades agropecuárias, não tendo recebido investimentos e
quase nenhum crédito financeiro externo para incrementar seu desenvolvimento.
Exceção feita ao dinheiro proveniente da venda de escravos para o sul do país. "

No começo da década de 1850 , o governo da província interviu na cotonicultura local comprando uma máquina descaroçadora de algodão, com a finalidade de aumentar a produtividade da produção de fios. Concomitantemente uma nova modalidade de algodão foi introduzida nas lavouras cearenses permitindo uma melhora na sua produtividade ${ }^{1}$. O resultado destes esforços se traduziu em um grande aumento na produção cearense de algodão. A maior parte da produção estava destinada ao mercado internacional, enquanto que apenas uma pequena fração era aproveita localmente na produção artesanal de tecidos.

De um ano para outro, a província cobriu-se de algodão: derribaram-se as mattas seculares do litoral às serras, das serras ao sertão; o agricultor com o machado em

\footnotetext{
${ }^{1} \mathrm{Em}$ 1852, foi introduzida uma variante de semente de algodão: Gossypium Hirsutum (SILVA, 2011)
}

\begin{tabular}{llllll}
\hline REVISTA ECONOMIA POLÍTICA DO DESENVOLVIMENTO & Maceió - AL & V.5 N.7. & JUNHO/2018 & P.98-111 & Página-102
\end{tabular}


uma das mãos e o facho na outra deixava após si ruinas enegrecidas. Os homens descuidavam-se da mandioca e dos legumes, as próprias mulheres abandonavam os teares pelo plantio do precioso arbusto: era uma febre que a todos halucinava, a febre da ambição (SOUSA apud SILVA, 2011).

Dadas as precárias condições de transporte, por meio de vias terrestres em direção a outras províncias. A produção de algodão cearense dispunha da via marítima, como única alternativa para o escoamento em direção ao mercado comprador. Basicamente a Inglaterra era o principal mercado para a cotonicultura cearense, provavelmente o único mercado comprador.

Assim posto, o algodão cearense representava a matéria-prima para a Revolução Industrial, porém apenas como um fornecedor de pouca expressão.Por meio do algodão eram produzidos e exportados tecidos para o mundo todo, a partir dos portos da Inglaterra. As exportações de algodão pelo Porto de Fortaleza aumentaram substancialmente a partir da segunda metade do século XIX.

Os dados da tabela 2 mostram as exportações de algodão pelo porto de Fortaleza entre 1845/6 e 1856/7. As informações fornecidas para este período registram os movimentos de mercadorias incorporando as transações ocorridas entre o segundo semestre de um ano e o primeiro semestre do ano subsequente. Em linhas gerais, as exportações de algodão cresceram substancialmente. Em 1849/50 foram exportadas 368 toneladas de algodão. Em 1850/51, 717 toneladas; e em 1855/6 foram transportadas 954 toneladas. A economia local ganhava mais recursos, tanto pelo aumento na produção física, como pelo aumento no preço médio ${ }^{2}$.

Tabela 2: Exportação de Algodão no Porto de Fortaleza, 1845 a 1856.

\begin{tabular}{ccccc}
\hline Ano & $\begin{array}{c}\text { Quantidade em } \\
\text { Toneladas }\end{array}$ & $\begin{array}{c}\text { Valor em } \\
\text { Mil Reis }\end{array}$ & $\begin{array}{c}\text { Preço Médio } \\
\text { em Reis }\end{array}$ & $\begin{array}{c}\text { Preço Médio } \\
(\mathbf{1 8 6 5 / 6}=\mathbf{1 0 0})\end{array}$ \\
\hline $\mathbf{1 8 4 5 - 6}$ & 124,8 & $39.981,0$ & 320,4 & 36,1 \\
\hline $\mathbf{1 8 4 6 - 7}$ & 46,38 & $12.632,0$ & 272,4 & 30,7 \\
\hline $\mathbf{1 8 4 7 - 8}$ & 249,6 & $73.207,0$ & 293,3 & 33,1 \\
\hline $\mathbf{1 8 4 8 - 9}$ & 511,3 & $131.397,0$ & 257,0 & 29,0 \\
\hline $\mathbf{1 8 4 9 - 0}$ & 368,2 & $110.317,0$ & 299,6 & 33,8 \\
\hline $\mathbf{1 8 5 0 - 1}$ & 717,3 & $270.596,0$ & 377,2 & 42,5 \\
\hline $\mathbf{1 8 5 1 - 2}$ & 630,3 & $201.728,7$ & 320,1 & 36,1 \\
\hline $\mathbf{1 8 5 2 - 3}$ & 991,6 & $340.991,1$ & 343,9 & 38,8 \\
\hline $\mathbf{1 8 5 3 - 4}$ & 746,9 & $300.071,0$ & 401,8 & 45,3 \\
\hline $\mathbf{1 8 5 4 - 5}$ & 703,3 & $237.875,6$ & 338,2 & 38,1 \\
\hline $\mathbf{1 8 5 5}-6$ & 954,1 & $357.163,2$ & 374,3 & 42,2 \\
\hline $\mathbf{1 8 5 6}-7$ & 904,3 & $369.468,0$ & 408,6 & 46,0 \\
\hline
\end{tabular}

Fonte:Girão (2000, p. 226-228)

Embora as exportações de algodão tenham crescido substancialmente, isto não representava que a renda proporcionada pela cotonicultura tenha permanecido em solo

\footnotetext{
${ }^{2}$ Entre 1845 e 1849, o preço médio da tonelada de algodão exportada aumentou de 32,54 Reis, para 40,15 Reis, com relação ao período entre 1850 e 1855 . Um aumento de 23,4\%. 
cearense. Segundo Silva (2011), em quanto durou o surto algodoeiro, ingressou uma quantidade substancial de capital para a província do Ceará. Os portos de Fortaleza, Acaraú e Aracati, que escoaram a produção para o exterior, vivenciaram uma fase de crescimento sem precedentes. Contudo, isto não se traduziu em uma melhora nas condições de infraestrutura econômica, pelo contrário havia dificuldades nas condições de embarque do algodão nos portos cearenses.Boa parte da renda do algodão foi para as províncias vizinhas, em pagamento pela compra de gêneros alimentícios, visto que a província não era autossuficiente na produção de mantimentos para o seu consumo. Outra parte foi gasta na compra de produtos supérfluos e na aquisição de materiais para a construção civil mais sofisticados.

\section{A GUERRA DE SECESSÃO AMERICANA E OS SEUS IMPACTOS SOBRE A COTONICULTURA CEARENSE}

Desde o começo da Revolução Industrial o maior mercado consumidor de algodão era a Grã-Bretanha. Em 1850, além da indústria têxtil, os britânicos concentravam grande parte da produção mundial de carvão e de produtos metalúrgicos. Segundo Saes e Saes (2015, p 273), a supremacia industrial britânica proporcionava uma situação privilegiada no comercio internacional, tanto em relação aos países mais adiantados, como aos países cuja economia era essencialmente primária. Para as economias primárias, como o Brasil, a Grã-Bretanha representava o principal mercado para escoamento de sua produção, além de constituir mercado consumidor para seus produtos industrializados.

$\mathrm{Na}$ década de 1850, os Estados Unidos eram o principal fornecedor de algodão para as indústrias britânicas. Em 1860, três em cada quatro arrobas de algodão compradas pelos ingleses era proveniente dos Estados Unidos. O segundo maior fornecedor era a Índia com uma em cada seis arrobas de algodão importadas. A participação brasileira era bem modesta com quase $3 \%$ do total importado.

O fluxo de comercio algodoeiro, entre a Inglaterra e Estados Unidos seria cortado, com o início da guerra de secessão entre os Estados da Confederação e dos Estados da União. Este evento externo representou uma grande oportunidade para que a região do semiárido nordestino saísse da dependência da agricultura de subsistência e da pecuária bovina.

O Brasil, e particularmente para a economia cearense, este evento foi profundamente benéfico em razão do com o embargo as exportações de algodão dos Estados Confederados. Conforme os dados apresentados no gráfico 2 , os preços do algodão vendidos no porto de Fortaleza aumentaram consideravelmente, alcançando o dobro do preço em 1862/3, e permanecendo elevados até o final do conflito em 1865. Após este período, se verifica uma tendência de redução nos preços desta mercadoria. 


\section{Gráfico 2}

(Preço médio da tonelada de algodão: $(1865 / 6=100)$

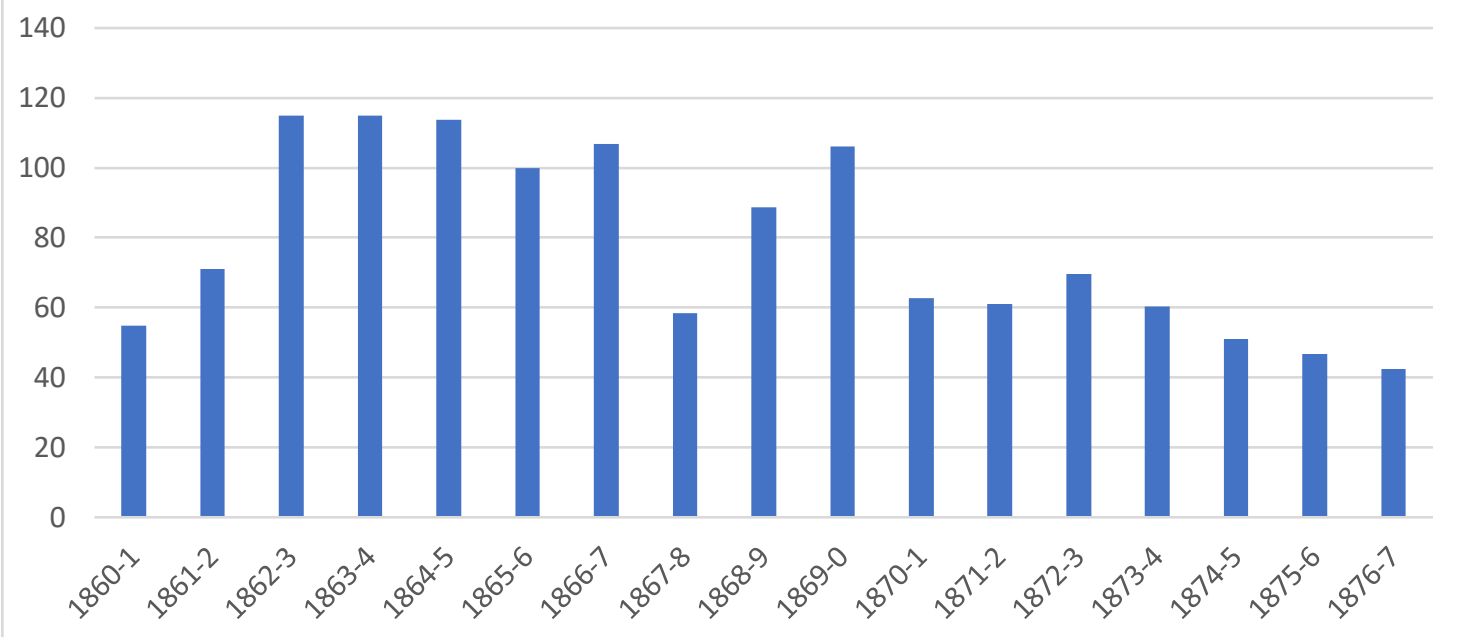

Fonte: Girão (2000, p. 226-228)

Os dados da tabela 3 mostram as exportações de algodão pelo porto de Fortaleza entre 1855/6 e 1864/5, período que antecede a Guerra de Secessão e o seu final. Os dados mostram que o valor de algodão exportado em moeda nacional tenha crescido, entre 1859/60 e 1864/5 em aproximadamente em $137 \%$, ele não ocorreu de forma continua e uniforme. Nos dois períodos seguintes (1860/1 e 1861/2) verificou-se uma queda no valor da produção. Somente no período de 1862/3 é o valor exportado consegue superar o registrado em 1859/60, em função do aumento do valor da tonelada exportada.

Tabela 3: Exportação de Algodão no Porto de Fortaleza, 1855 a 1865

\begin{tabular}{ccccc}
\hline Ano & $\begin{array}{c}\text { Quantidade em } \\
\text { Toneladas }\end{array}$ & $\begin{array}{c}\text { Valor em } \\
\text { Mil Reis }\end{array}$ & $\begin{array}{c}\text { Preço Médio } \\
\text { em Reis }\end{array}$ & $\begin{array}{c}\text { Preço Médio } \\
(\mathbf{1 8 6 5 / 6}=\mathbf{1 0 0})\end{array}$ \\
\hline $\mathbf{1 8 5 5 - 6}$ & 954,1 & $357.163,2$ & 374,3 & 42,2 \\
\hline $\mathbf{1 8 5 6 - 7}$ & 904,3 & $369.468,0$ & 408,6 & 46,0 \\
\hline $\mathbf{1 8 5 7 - 8}$ & $1.128,20$ & $519.573,3$ & 460,5 & 51,9 \\
\hline $\mathbf{1 8 5 8 - 9}$ & $1.091,40$ & $524.658,6$ & 480,7 & 54,2 \\
\hline $\mathbf{1 8 5 9 - 0}$ & $1.139,40$ & $596.318,3$ & 523,4 & 59,0 \\
\hline $\mathbf{1 8 6 0 - 1}$ & 863,5 & $419.810,0$ & 486,2 & 54,8 \\
\hline $\mathbf{1 8 6 1 - 2}$ & 745,9 & $470.479,8$ & 630,8 & 71,1 \\
\hline $\mathbf{1 8 6 2}-3$ & 646,1 & $659.235,0$ & 1020,3 & 115,0 \\
\hline $\mathbf{1 8 6 3 - 4}$ & 888,3 & $906.332,5^{*}$ & $1020,3 *$ & $115,0^{*}$ \\
\hline $\mathbf{1 8 6 4 - 5}$ & $1.403,3$ & $1.415 .096,3$ & 1008,4 & 113,7 \\
\hline
\end{tabular}

Fonte: Girão (2000, p. 226-228). ${ }^{3}$

\footnotetext{
3* Devido à escassez de dados, supõe-se que as médias não tenham sido alteradas, entre 1862/3 e 1863/4. Para 1863/4, o valor das exportações foi calculado com base no volume físico exportado vezes o preço médio do período anterior. 
Antes do conflito, a tonelada exportada era vendida por quase quinhentos reis, valor equivalente a um dia de trabalho no campo. Com o início do bloqueio dos Estados Unidos aos portos Confederados, o fornecimento de algodão norte-americano é praticamente eliminado, provocando na Inglaterra um colapso na produção da indústria têxtil, que dependia integralmente de matéria prima importada. Em 1861, os britânicos importavam dos Estados Unidos quase dois milhões e quinhentas mil de arrobas de algodão. No ano seguinte, somente 72 arrobas.

Como resultado da escassez de algodão no mercado internacional, seu preço aumenta consideravelmente, beneficiando diretamente outras regiões algodoeiras, consideradas como produtoras marginais, tais como o Brasil e as colônias britânicas do Egito e da Índia. Isto torna-se bem claro quando observamos a tabela 4: enquanto as importações inglesas de algodão provenientes dos Estados Unidos caiam, aumentavam as compras desta mercadoria no Brasil, Índia e Egito. Embora a produção destes três mercados produtores tenha crescido consideravelmente, em conjunto eles não conseguem abastecer com eficiência as manufaturas inglesas. Um bom exemplo disso, é que as exportações conjuntas dos três países durante o conflito, nunca tenha conseguido superar as exportações de algodão norte-americano para a Inglaterra. Como resultado disso, os preços do algodão no mercado internacional dispararam. Em 1861, a libra de algodão era vendida no mercado britânico, em média por 8,5 pences. Em 1862, seu preço havia mais que duplicado, chegando ao patamar de 18,37 pences por uma libra de algodão.

Tabela 4: Importações de algodão da Grã-Bretanha entre 1860 e 1865 (em mil arrobas)

\begin{tabular}{ccccccc}
\hline Ano & $\begin{array}{c}\text { Estados } \\
\text { Unidos }\end{array}$ & Índia & Brasil & Egito & Total & $\begin{array}{c}\text { Preço (pence } \\
\text { por libra) }\end{array}$ \\
\hline 1860 & 2.581 & 563 & 103 & 110 & 3.367 & 5,97 \\
\hline 1861 & 1.842 & 987 & 100 & 98 & 3.036 & 8,5 \\
\hline 1862 & 72 & 1.072 & 134 & 147 & 1.445 & 18,37 \\
\hline 1863 & 132 & 1.391 & 138 & 249 & 1.932 & 22,46 \\
\hline 1864 & 198 & 1.799 & 212 & 319 & 2.587 & 27,17 \\
\hline 1865 & 462 & 1.408 & 340 & 414 & 2.755 & 19,11 \\
\hline
\end{tabular}

Fonte:WRIGHT (1974)

\section{OS IMPACTOS DE FIM DA GUERRA DE SECESSÃO AMERICANA SOBRE A COTONICULTURA CEARENSE}

Com o fim da guerra de Secessão, às condições externas que fomentaram a expansão do cultivo do algodão na província do Ceará haviam mudado. É natural supor que após o fim do conflito, as antigas redes de comércio seriam reestabelecidas e os volumes de mercadorias voltariam para patamares anteriores. O mercado produtor de algodão havia se desconcentrado e torando-se mais competitivo. Em 1860 os Estados Unidos representavam 3 de cada 4 toneladas de algodão importadas pela Inglaterra. Em 1870, esta relação havia caído de 1 para 2. 
Se para os Estados Unidos o mercado mundial de algodão estava mais competitivo, com mais países produtores. Para o Brasil as condições para o desenvolvimento da cotonicultura tornaram-se adversas. Não havia um mercado nacional em condições absorver a produção de algodão. Praticamente toda a produção era vendida ao exterior. Segundo Davis (2002, p 402-403): "o algodão de excelente qualidade dos Estados Unidos logo inundaria o mercado mundial".

Tabela 5: Importações de algodão da Grã-Bretanha entre 1865 a 1875 (em mil arrobas)

\begin{tabular}{ccccccc}
\hline Ano & $\begin{array}{c}\text { Estados } \\
\text { Unidos }\end{array}$ & Índia & Brasil & Egito & Total & $\begin{array}{c}\text { Preço (pence } \\
\text { por libra) }\end{array}$ \\
\hline 1865 & 462 & 1.408 & 340 & 414 & 2.755 & 19,11 \\
\hline 1866 & 1.163 & 1.867 & 408 & 200 & 3.749 & 15,3 \\
\hline 1867 & 1.226 & 1.511 & 437 & 198 & 3.501 & 10,98 \\
\hline 1868 & 1.269 & 1.452 & 637 & 201 & 3.660 & 10,52 \\
\hline 1869 & 1.040 & 1.496 & 514 & 227 & 3.383 & 12,12 \\
\hline 1870 & 1.664 & 1.064 & 403 & 219 & 3.462 & 9,89 \\
\hline 1871 & 2.249 & 1.236 & 515 & 272 & 4.405 & 8,55 \\
\hline 1872 & 1.403 & 1.236 & 717 & 305 & 3.880 & 10,78 \\
\hline 1873 & 1.898 & 1.288 & 472 & 328 & 3.904 & 9,65 \\
\hline 1874 & 1.958 & 1.041 & 498 & 300 & 3.915 & 8,36 \\
\hline
\end{tabular}

Fonte: WRIGHT (1974)

O que realmente aconteceu em seguida foi uma catástrofe para a cotonicultura cearense. Para compensar a sua perda de competitividade, os produtores cearenses aumentaram a produção, aumentado a oferta. Como consequência de não haver uma demanda para absorver este excedente, isto proporcionou uma forte tendência de queda nos preços do produto e arruinando a vida dos pequenos produtores rurais.

Este cenário desolador, também pode ser percebido com base das exportações brasileiras entre 1861 a 1876. Os dados da tabela 6 sinalizamuma tentativa dos produtores rurais brasileiros em manter sua renda, ao aumentar a produção de forma a tentar compensar a redução nos preços dos mercados internacionais.

Tabela 6: Brasil e Estados Unidos: Exportações de algodão em toneladas

\begin{tabular}{lcc}
\hline Média anual do período & Brasil & Estados Unidos \\
\hline $1861-1864$ & 14.900 & 4.300 \\
\hline $1865-1868$ & 37.700 & 315.800 \\
\hline $1869-1872$ & 50.700 & 258.100 \\
\hline $1872-1876$ & 41.900 & 634.600 \\
\hline
\end{tabular}

Fonte: Albuquerque apud Viana (1990) ${ }^{4}$.

${ }^{4}$ Os dados para Brasil são para os anos de 1862,1863 e 1864. 
Enquanto o setor algodoeiro tentava manter sua renda produzindo mais algodão, para compensar a queda nos preços internacionais. Os efeitos sobre o mercado brasileiro foram mais sentidos na região do semiárido nordestino.

\footnotetext{
"Os sertanejos desesperados tentaram compensar produzindo ainda mais algodão. Mas enquanto faixas de lavouras floresciam nos mais remotos cantos do sertão, os produtores caíam vítimas de um torniquete entre os preços de mercado em queda e os altos e rígidos custos mundiais do transporte por terra para os portos fluviais mais próximos (DAVIS, 2002)."
}

No Ceará, a cotonicultura entrou em crise, deixando os proprietários de terras endividados e uma grande parte deles, com propriedades hipotecadas. Uma parcela considerável dos camponeses viu-se obrigado a trabalhar para terceiros para sobreviver, o que levou a um aumento na oferta de mão de obra e consequentemente uma redução no valor da hora trabalhada. Embora em crise, o algodão representava a principal riqueza da província. As outras culturas apenas complementavam a renda da economia local.

Tabela 7: Exportação de Algodão no Porto de Fortaleza, 1865 a 1876.

\begin{tabular}{ccccc}
\hline Ano & $\begin{array}{c}\text { Quantidade em } \\
\text { Toneladas }\end{array}$ & $\begin{array}{c}\text { Valor em } \\
\text { Mil Reis }\end{array}$ & $\begin{array}{c}\text { Preço Médio } \\
\text { em Reis }\end{array}$ & $\begin{array}{c}\text { Preço Médio } \\
(\mathbf{1 8 6 5} / 6=\mathbf{1 0 0})\end{array}$ \\
\hline $\mathbf{1 8 6 5 - 6}$ & $2.002,1$ & $1.776 .326,0$ & 887,2 & 100,0 \\
\hline $\mathbf{1 8 6 6 - 7}$ & $2.380,9$ & $2.256 .927,0$ & 947,9 & 106,8 \\
\hline $\mathbf{1 8 6 7 - 8}$ & $4.332,4$ & $2.249 .267,0$ & 519,2 & 58,5 \\
\hline $\mathbf{1 8 6 8 - 9}$ & $4.686,3$ & $3.684 .815,0$ & 786,3 & 88,6 \\
\hline $\mathbf{1 8 6 9 - 0}$ & $5.219,1$ & $4.911 .190,0$ & 941,0 & 106,1 \\
\hline $\mathbf{1 8 7 0 - 1}$ & $7.253,9$ & $4.033 .040,0$ & 556,0 & 62,7 \\
\hline $\mathbf{1 8 7 1 - 2}$ & $8.324,3$ & $4.503 .356,0$ & 541,0 & 61,0 \\
\hline $\mathbf{1 8 7 2 - 3}$ & $4.970,0$ & $3.070 .278,0$ & 617,8 & 69,6 \\
\hline $\mathbf{1 8 7 3 - 4}$ & $4.878,0$ & $2.608 .364,0$ & 534,7 & 60,3 \\
\hline $\mathbf{1 8 7 4 - 5}$ & $5.738,1$ & $2.599 .072,0$ & 452,9 & 51,1 \\
\hline $\mathbf{1 8 7 5 - 6}$ & $3.505,6$ & $1.456 .224,0$ & 415,4 & 46,8 \\
\hline
\end{tabular}

Fonte: GIRÂO (2000, p. 226-228)

\section{A GRANDE SECA DE 1876 A 1871 E OS SEUS IMPACTOS SOBRE A ECONOMIA.}

No século XIX, foram registradas grandes secas nos anos de 1809, 1824 a 1825, 1844 a 1845, e entre 1877 a 1879. Entre 1845 e 1877, foi 32 anos de invernos regulares que registraram pequenas secas e grandes invernos, o que representava um relativo cenário de estabilidade para a sobrevivência do homem do campo. No último quartel do século XIX, já se havia esquecido na sociedade das grandes secas que afetaram a economia da região, como a de 1825 que reduziu a população do Ceará em 25 mil pessoas (DAVIS: 2002, p. 397). Porém, está relativa "calma" seria quebrada no triênio 1877-79, quando a precipitação pluviométrica 
registrada fora aproximadamente um terço da média verificada nas últimas três décadas. Para uma economia baseada na agricultura e na pecuária, estas condições climáticas teriam consequências catastróficas para população.

\section{Gráfico 3}

Fortaleza: dias de Chuvas entre 1849 e 1890

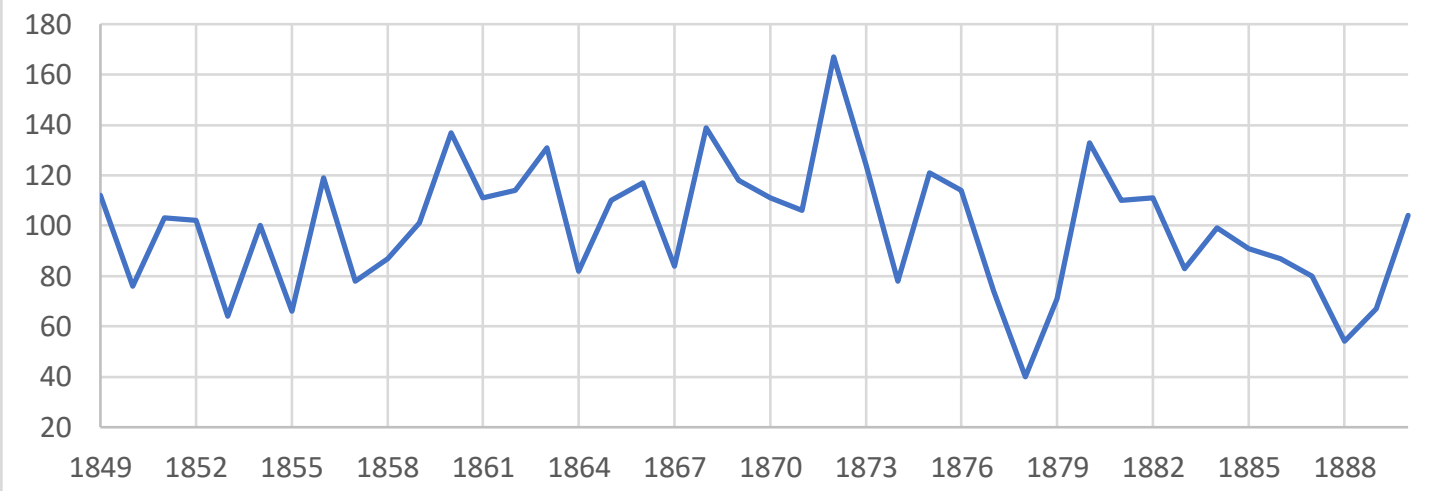

Fonte: Theophilo (1922, p 12)

\section{Gráfico 4}

Precipitação em Fortaleza: 1849 a 1890 (em milímetros)

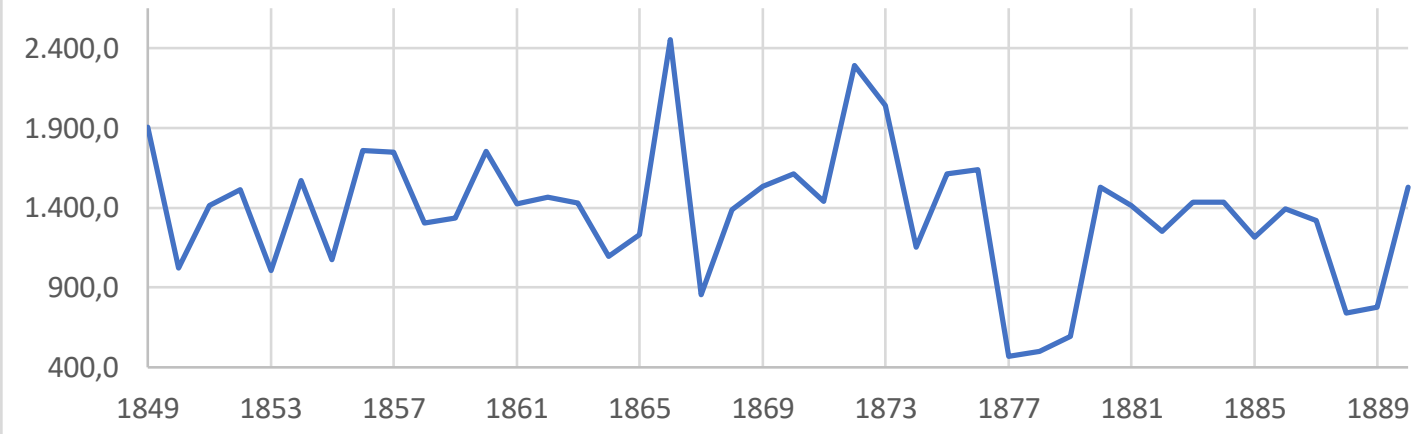

Fonte: Theophilo (1922, p 12)

Em uma economia essencialmente agrária, a secas de 1877 a 1879 foram bastante prejudiciais para economia cearense. Com três anos de estações chuvosas deficientes, os efeitos sobre a agricultura foram danosos. As exportações de algodão caíram sensivelmente de 3.506 toneladas no período de 1875/1876, para 630 toneladas em 1878/79. O que se pode observa na tabela 8 é que: em quatro anos as exportações de algodão sofreram um grande impacto ao ser reduzido em $82 \%$. A condição de normalidade retornaria anos depois, somente em 1881/82 é que elas voltariam ao patamar anterior. 
Tabela 8: Exportação de Algodão no Porto de Fortaleza, 1876 a 1886.

\begin{tabular}{ccccc}
\hline Ano & $\begin{array}{c}\text { Quantidade em } \\
\text { Toneladas }\end{array}$ & $\begin{array}{c}\text { Valor em } \\
\text { Mil Reis }\end{array}$ & $\begin{array}{c}\text { Preço Médio } \\
\text { em Reis }\end{array}$ & $\begin{array}{c}\text { Preço Médio } \\
(\mathbf{1 8 6 5} / \mathbf{6}=\mathbf{1 0 0})\end{array}$ \\
\hline $\mathbf{1 8 7 5 - 6}$ & $3.505,6$ & $1.456 .224,0$ & 415,4 & 46,8 \\
\hline $\mathbf{1 8 7 6 - 7}$ & $3.082,4$ & $1.163 .314,0$ & 377,4 & 42,5 \\
\hline $\mathbf{1 8 7 7 - 8}$ & $1.214,6$ & $444.485,3$ & 366,0 & 41,2 \\
\hline $\mathbf{1 8 7 8 - 9}$ & 628,9 & $283.214,0$ & 450,3 & 50,8 \\
\hline $\mathbf{1 8 7 9 - 0}$ & 683,9 & $354.695,0$ & 518,6 & 58,5 \\
\hline $\mathbf{1 8 8 0 - 1}$ & $2.071,6$ & $945.553,0$ & 456,4 & 51,4 \\
\hline $\mathbf{1 8 8 1 - 2}$ & $5.270,3$ & $2.262 .849,5$ & 429,4 & 48,4 \\
\hline $\mathbf{1 8 8 2 - 3}$ & $4.345,7$ & $1.911 .286,0$ & 439,8 & 49,6 \\
\hline $\mathbf{1 8 8 3 - 4}$ & $4.433,7$ & $1.830 .552,2$ & 412,9 & 46,5 \\
\hline $\mathbf{1 8 8 4 - 5}$ & $3.072,2$ & $1.300 .005,7$ & 423,2 & 47,7 \\
\hline $\mathbf{1 8 8 5 - 6}$ & $3.159,5$ & $1.342 .360,1$ & 424,9 & 47,9 \\
\hline
\end{tabular}

Fonte: GIRÂO (2000, p. 226-228).

\section{CONCLUSÕES}

A economia cearense, desde período colonial até as últimas décadas do século XX, esteve baseada no setor primário. Embora algumas industrias tenham surgido no final do século XIX, o motor principal da economia permanecia ligado ao campo. Assim, as condições climáticas sempre tiveram uma fundamental importância para a sobrevivência dos camponeses. Desde o século XVII, a colonização pelos portugueses seguiu a ótica do gado bovino a partir do rio São Francisco em direção ao litoral do cearense. Com a pecuária extensiva vinha também, a agricultura de subsistência que fornecia, em conjunto com a criação do gado bovino, ao homem do campo suas necessidades fundamentais. Pode-se afirmar que a monetização das atividades era extremamente reduzida.

Este cenário de baixa monetização iria mudar, com a introdução do cultivo de algodão no começo do século XIX e o início da Guerra de Secessão nos Estados Unidos. Este conflito sangrento proporcionou uma grande oportunidade econômica para a economia do Ceará. Com terras baratas e mão-de-obra abundante, a cultura do algodão prosperou ajudada por invernos regulares desde 1845 . A região experimentou pela primeira vez um período de riqueza para seus habitantes.

Embora os preços tendessem a declinar, após o restabelecimento dos Estados Unidos como fornecedor de algodão. A cotonicultura cearense compensou a queda nos preços com aumento na produção. Esta estratégia manteve relativo sucesso até a grande seca de 1877 a 1879. A grande seca afetou diretamente as exportações de algodão. Somente em 1881/2 é que elas conseguiram retornar aos patamares anteriores. Assim, dois fatores externos foram responsáveis pelas transformações na economia cearense no século XIX: o algodão e a seca. 


\section{REFERÊNCIA BIBLIOGRAFICA}

ANDRADE, Manoel Correia. A intervenção do Estado e a seca no Nordeste do Brasil. Fortaleza: Revista Econômica do Nordeste, volume 6, n 4, outubro-dezembro, p. 125-130, 1986.

BERNSTEIN, William J. Uma breve história da riqueza. São Paulo: Editora Fundamento, 2015.

BOLT, J. and J. L. van Zanden (2014). The Maddison Project: collaborative research on historical national accounts.The EconomicHistory Review, 67 (3): 627-651.

BRASIL, Thomas Pompeu de Souza. População do Ceará em 1879. Fortaleza: Instituto do Ceará Histórico, Geográfico e Antropológico. Ano IV, vol.1, p. 253-272, 1890.

BRASIL, Thomaz Pompeo de Sousa. Ensaio estatístico da Província do Ceará/Thomaz Pompeo de Sousa Brasil. - Edição fac-símile publicada em 1863 - Fortaleza: Fundação Waldemar de Alcântara, 1997.

BRASIL: IBGE http://biblioteca.ibge.gov.br/biblioteca-catalogo?view=detalhes\&id=225477. Acessado em 25 de maio de 2018.

COSTA, Maria Clélia Lustosa. Teorias médicas e gestão urbana: a seca de 1877-79 em Fortaleza. Rio de Janeiro: História Ciências Saúde-Manguinhos, v. 11, n. 1, Abril 2004.

CUNNIFF, Roger. The Birth of the Drought Industry: Imperial and Provincial Responses to the Great Drought in Northeast Brazil (1877-1880). Revista de Ciências Humanas, 1975.

DAVIS, Mike. Holocausto coloniais: clima, fome e imperialismo na formação do Terceiro Mundo. Rio de Janeiro: Record, 2002.

FARIA, Airton. História do Ceará. Fortaleza: Editora Armazém da Cultura, 2012.

GIRÃO, Raimundo. História Econômica do Ceará. Fortaleza: Editora UFC - Casa José Alencar, 2000. $2^{\mathrm{a}}$. Edição.

MAIA. Janille Campos. Exilados da Fome: Seca e Migração no Ceará. Dissertação (mestrado) Seropédica: Universidade Federal Rural do Rio de Janeiro, Instituto de Ciências Humanas e Sociais, Dissertação de Mestrado, 2015 (mimeo).

MARCÍLIO, Maria Luiza. Crescimento histórico da população brasileira até 1872. Cadernos Cebrap, v. 16, p. 01-26, 1973. Disponível em: www.cebrap.org.br/v2/files/upload/.../crescimento_historico_da_populacao.pdf Acessado em 25 de maio de 2018.

NEVES, Frederico de Castro. A seca na história do Ceará. In SIMONE DE SOUZA, Adelaide Gonçalves org. Uma nova história do Ceará. Fortaleza: Edições Demócrito Rocha, 2007.

SAES, FAM; SAES, A. M. História econômica geral. São Paulo: Saraiva, 2013.

STUART, Guilherme Barão de. Climatologia, epidemias e endemias do Ceará/ Guilherme Barão de Stuart. Edição fac-símile - Fortaleza: Fundação Waldemar de Alcântara, 1997. Coleção Biblioteca Básica Cearense.

STUART, Guilherme Barão de. Datas e factos para a história do Ceará/ Guilherme Barão de Stuart. Edição fac-símile. Fortaleza: Fundação Waldemar de Alcântara, 2001. Coleção Biblioteca Básica Cearense.

The Maddison-Project. http://www.ggdc.net/maddison/maddison-project/home.htm, 2013 version. Acessado em 20 de maio de 2018.

THEOHILO, Rodolfo. História da Seca do Ceará (1877-1880). Imprensa Inglesa, Rio de Janeiro, 1922.

VIANA, Carlos Negreiros. Os fatores determinantes do primeiro surto de investimentos em indústria têxtil no Ceará: 1881- 1895. Fortaleza: Revista Econômica do Nordeste, volume 21, n 1, janmarço, p. 67-106, 1990.

WRIGHT, Gavin. Cotton Competition and the Post-Bellum Recovery of the American South. The Journal of Economic History, Vol. 34, No. 3 (Sep., 1974), pp. 610-635.

DE MOURA FILHO, Heitor Pinto. Câmbio de longo prazo do mil-réis: uma abordagem empírica referente às taxas contra a libra esterlina e o dólar (1795-1913. Cadernos de História, v. 11, n. 15, p. 9-34, 2010. 